\title{
Analysis of new species retrieved from MIPAS
}

\author{
Shaomin Cai ${ }^{*}$, Anu Dudhia \\ University of Oxford \\ cai@atm.ox.ac.uk
}

\begin{abstract}
The Michelson Interferometer for Passive Atmospheric Sounding (MIPAS) instrument which operated on the Envisat satellite from 2002-2012 is a Fourier transform spectrometer for the measurement of high-resolution gaseous emission spectra at the Earth's limb. It operates in the near- to mid-infrared, where many of the main atmospheric trace gases have important emission features. The initial operational products were profiles of Temperature, $\mathrm{H} 2 \mathrm{O}, \mathrm{O} 3, \mathrm{CH} 4, \mathrm{~N} 2 \mathrm{O}$, HNO3, and NO2, and this list was recently extended to include N2O5, ClONO2, CFC-11 and CFC-12. Here we present preliminary results of retrievals of the third set of species under consideration for inclusion in the operational processor: HCN, CF4, HCFC-22, COF2 and CCl4.
\end{abstract}

\section{INTRODUCTION}

$\mathrm{T}$ he Michelson Interferometer for Passive Atmospheric Sounding (MIPAS), which operated on the Envisat satellite from 2002-2012, is a Fourier transform spectrometer for the measurement of emission spectra at the Earth's limb. It operates in the near- to midinfrared where many of the main atmospheric trace gases have detectable emission features. The initial operational products were profiles of Temperature, $\mathrm{H}_{2} \mathrm{O}, \mathrm{O}_{3}, \mathrm{HNO}_{3}, \mathrm{CH}_{4}, \mathrm{~N}_{2} \mathrm{O}$ and $\mathrm{NO}_{2}$, and this list was recently extended to include $\mathrm{N}_{2} \mathrm{O}_{5}, \mathrm{ClONO}_{2}, \mathrm{CFC}-11$ and CFC- 12 .

In this paper the preliminary results of a third set of species, HCN, CFC-14 ( $\left.\mathrm{CF}_{4}\right), \mathrm{HCFC}-22$, $\mathrm{COF}_{2}, \mathrm{CCl}_{4}, \mathrm{SF}_{6}, \mathrm{OCS}, \mathrm{HOCl}$ and $\mathrm{C}_{2} \mathrm{H}_{6}$, retrieved using the Oxford L2 processor, MORSE (Multispectral Optimal Retrievals using Sequential Estimation), are presented.

$\mathrm{HCN}, \mathrm{OCS}$ and $\mathrm{C}_{2} \mathrm{H}_{6}$ are tracers of biomass burning (Rinsland et al., 1998; Li et al., 2000;
Notholt et al., 2003; Logan et al., 1981). The relatively long lifetimes for $\mathrm{HCN}$ and $\mathrm{C}_{2} \mathrm{H}_{6}$ make them indicators of how transport redistributes pollutants on a global scale (Rinsland et al., 2005). $\mathrm{CCl}_{4}, \mathrm{CFC}-14, \mathrm{HCFC}-22$ and $\mathrm{SF}_{6}$ are mainly from anthropogenic emissions. For example CFC-14 are produced primarily as a byproduct during electrolytic aluminum production and $\mathrm{SF}_{6}$ is mainly from insulating electrical equipment. $\mathrm{SF}_{6}$ and $\mathrm{CF}_{4}$ are extremely longlived species and often used as tracers for the 'age of air'. $\mathrm{HOCl}$ is considered to be a reservoir for active chlorine, $\mathrm{ClOx}$, and odd hydrogen, $\mathrm{HOx}$, in the stratosphere (von Clarmann et al., 2012). It is produced primarily by the reaction of $\mathrm{ClO}$ and $\mathrm{HO}_{2}$ (peroxy radical) and is destroyed mainly by photo-dissociation, which returns $\mathrm{OH}$ and $\mathrm{Cl}$ radicals (Hickson et al., 2007).

Here we also examine fluorine species collectively measured by MIPAS. Stratospheric fluorine has important effects on the atmosphere, especially fluorine in long-lived greenhouse 
gases. Over the past few decades, the major sources of fluorine in the stratosphere are the man-made chlorofluorocarbons CFCs and HCFCs. Photolysis of these compounds forms $\mathrm{COF}_{2}$. The $\mathrm{COF}_{2}$ molecule has been shown to be the second most abundant stratospheric fluorine reservoir (Kaye et al., 1991).

\section{ZONAL MEAN DISTRIBUTIONS}

The Oxford L2 processor MORSE has been used to retrieve these new species with the microwindows shown in Fig.1. Here we analyze these new retrieved species to establish their zonal mean for the period of 2010 March.

For each gas, we eliminated those data points that are cloud-affected and where a priori has a significant contribution, in other words, the retrieved random error greater than $50 \%$ of the volume mixing ratio (VMR). A $5 \sigma$ global spike test is then applied to each species to eliminate unrealistic data. The percentage of profiles removed by the spike test is shown in Table 1 . The largest percentage showed in the table is $21.5 \%$ from CFC-14. Reasons for these spike test failures have yet to be investigated. As the total number of profiles for each species for one month is over 32,000 , there are still remaining a large number of profiles, over 25,000 profiles, to have a reliable sample basis for the further study.

The remaining profiles are used construct monthly zonal mean together with a standard deviation defined as the standard deviation of profiles contribute to each grid point, which is a combination of random error and atmosphere variability.

Zonal plots of species $\mathrm{CCl}_{4}$, OCS, HCFC-22, $\mathrm{SF}_{6}$, $\mathrm{C}_{2} \mathrm{H}_{6}$ and $\mathrm{COF}_{2}$ in Fig. 2 show the expected structure for tropospheric source gases. The
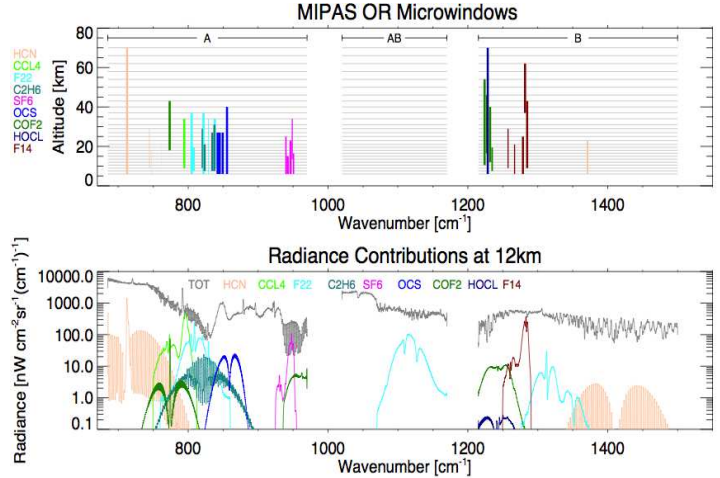

Fig. 1, Microwindows for the new species. The upper panel shows the microwindows selected for these new species retrievals. The lower panel show the spectral signatures of these species.

Table 1, percentage of removed profiles by $5 \sigma$ spike test.

\begin{tabular}{cc}
\hline Species & Ratio (\%) \\
\hline $\mathrm{CCl}_{4}$ & 1.9 \\
$\mathrm{COF}_{2}$ & 12.5 \\
$\mathrm{HCFC}-22$ & 0.5 \\
$\mathrm{HCN}$ & 5.2 \\
$\mathrm{CFC}^{2} 14$ & 21.5 \\
$\mathrm{SF}_{6}$ & 12.3 \\
$\mathrm{HOCl}$ & 0.03 \\
$\mathrm{C}_{2} \mathrm{H}_{6}$ & 18.7 \\
$\mathrm{CFC}-11$ & 1.6 \\
$\mathrm{CFC}-12$ & 2.6 \\
$\mathrm{OCS}$ & 2.0
\end{tabular}



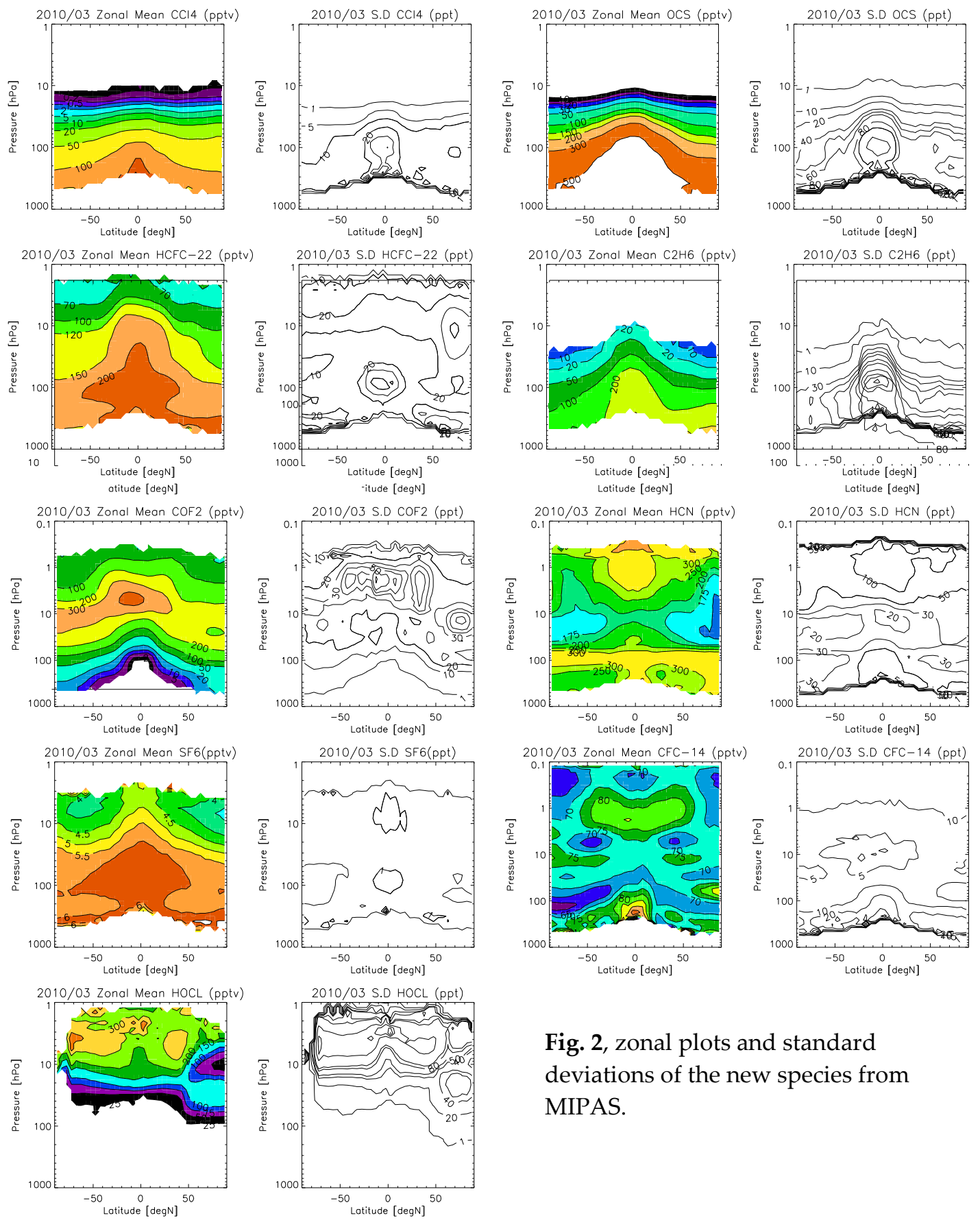

Fig. 2, zonal plots and standard deviations of the new species from MIPAS.

plot of $\mathrm{COF}_{2}$ also well represents the maximum of VMR around the middle of the stratosphere over equator. This occurs because

$\mathrm{COF}_{2}$ is an intermediate product in the degradation of CFCs in the stratosphere, which results in an increase of VMR. Also because $\mathrm{COF}_{2}$ is destroyed by photolysis and reaction 
with $\mathrm{O}(\mathrm{1D})$ in the upper stratosphere, which results in a decrease of VMR.

There are some unexpected features in the zonal plots for species CFC-14 and HCN. For example, a maximum VMR of HCN occurs near the stratopause over the equator, which seems unrealistic and requires comparison with other data sets. Similar for CFC-14 there is a maximum in the upper stratosphere over equator, which is unrealistic as well. Due to its complexity, $\mathrm{HOCl}$ species need further study before the data could be used for quantitative research.

\section{Total Fluorine}

The fluorine species measured by MIPAS are $\mathrm{COF}_{2}$, CFC-11, CFC-12, CFC-14, CFC-22 and $\mathrm{SF}_{6}$ from which the total fluorine can be computer as $[\mathrm{F}]=2\left[\mathrm{COF}_{2}\right]+[\mathrm{CFC}-11]+2[\mathrm{CFC}-12]+$ $4[\mathrm{CFC}-14]+2[\mathrm{CFC}-22]+6\left[\mathrm{SF}_{6}\right]$. Mahieu et. al. (2008) show most of the stratospheric fluorine species eventually form Hydrogen Fluoride (HF), which is not measured by MIPAS. Other fluorine containing species are comparable small compared with those measured by MIPAS and HF.

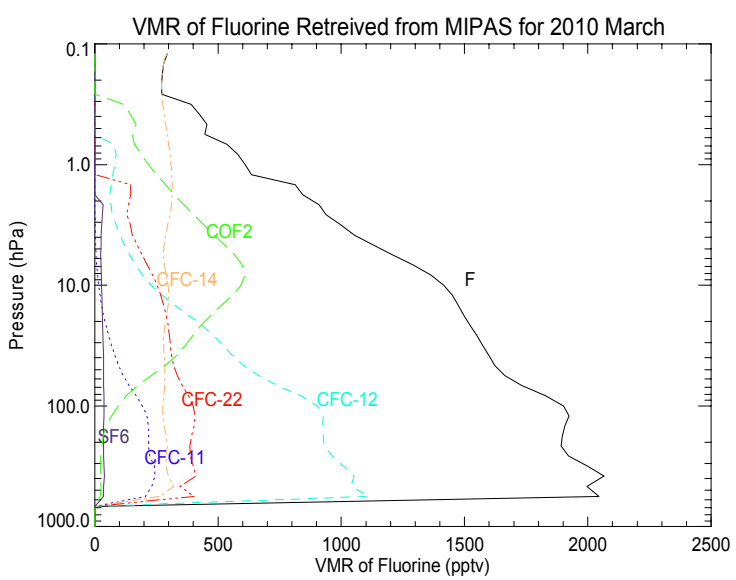

Fig. 3, The vertical profiles of all the fluorine containing species and the total fluorine retrieved by MIPAS.
Figure 3 shows the vertical profiles of all the fluorine species and total fluorine $(\mathrm{F})$ measured by MIPAS. In the lower stratosphere and upper troposphere, the atmospheric fluorine is mainly contributed by CFC-12. $\mathrm{COF}_{2}$ contributes nearly half of the fluorine $\mathrm{VMR}$ at $10 \mathrm{hPa}$ pressure level, while CFC-14 dominates in the upper stratosphere. The total [F] decreases with altitude as they are eventually formed into HF, which is not measured by MIPAS. The expected HF zonal plot for 2010 March is constructed by the following, $[\mathrm{HF}]=[$ Fmax $]-[\mathrm{F}]$, where $[F]$ is the total fluorine zonal mean measured by MIPAS and [Fmax] is the maximum value of [F]. This plot (Fig. 4) is further compared with the zonal plot of HF (fig. 5) produced by Jones et al., 2012. Fig 5 is a threemonth combined zonal average from ACE-FTS data during September-October-November. Fig 4 and Fig 5 is for brief comparison of MIPAS data with ACE-FTS data of HF zonal means.

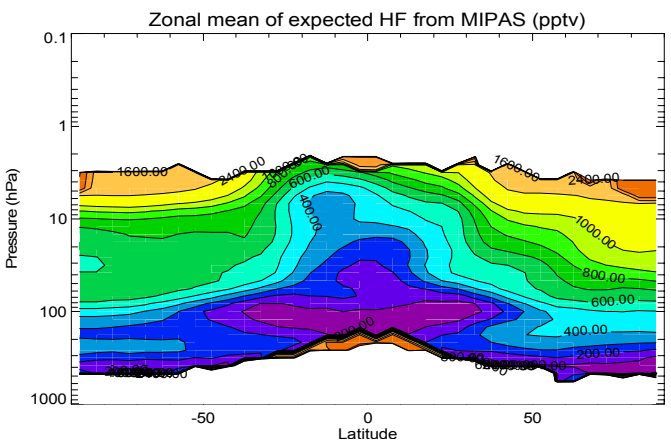

Fig. 4, expected zonal plot of HF from MIPAS

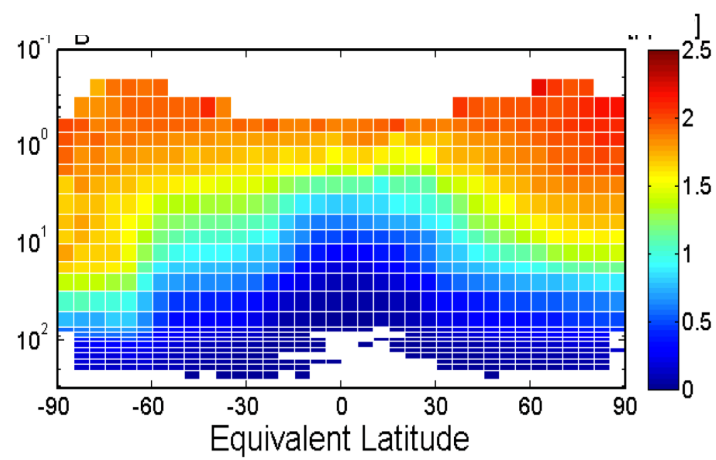

Fig. 5, zonal plot of HF from ACE-FTS (Jones et al., 2012) 


\section{CONCLUSIONS AND FUTURE WORK}

Plausible distributions of $\mathrm{HCFC}-22, \mathrm{COF}_{2}, \mathrm{CCl}_{4}$, $\mathrm{SF}_{6}$, OCS, $\mathrm{HOCl}$ and $\mathrm{C}_{2} \mathrm{H}_{6}$ retrieved by MIPAS, which CFC-14 and HCN have some anomalies requiring further investigation. However, further comparison with ACE-FTS, other MIPAS processor and model results are required for further justification.

\section{REFERENCES}

E. Mahieu et al., Validation of ACE-FTS v2.2 measurements of $\mathrm{HCl}, \mathrm{HF}, \mathrm{CCl}_{3} \mathrm{~F}$ and $\mathrm{CCl}_{2} \mathrm{~F}_{2}$ using space balloon and ground based instrument observations, Atmos. Chem. Phys. Discuss., 8, 3431-3495, 2008

Hickson, K. and L. Keyser et al., Temperature dependence of the $\mathrm{HO}_{2}+\mathrm{ClO}$ reaction.2. Reaction kinetics using the discharge-flow resonance-fluorescence technique, J. Phys.Chem. A, 111, 8126-8138, 2007.

Jones, A. and K. A. Walker et al., Technical Note: A trace gas climatology derived from the Atmospheric Chemistry Experiment Fourier Transform Spectrometer (ACE-FTS) data set, Atmos. Chem. Phys., 12, 5207-5220, 2012

Kaye, J. A. and A. R. Douglass et al., Twodimensional model calculation of fluorinecontaining reservoir species in the stratosphere, J. Geophys. Res. ,96, 12,865-12,881, 1991
Li, Q. and D. J. Jacob et al., Atmospheric hydrogen cyanide $(\mathrm{HCN})$ : Biomass burning source, ocean sink?, Geophys. Res. Lett., 27, 357360,2000

Logan, J. A. and M. J. Prather et al., Tropospheric chemistry: A global perspective, J. Geophys. Res., 86, 7210-7254, 1981

Notholt, J. and Z. Kuang et al., Enhanced upper topical tropospheric COS: Impact on the stratospheric aerosol layer, Science, 300, 307310, 2003

Rinsland, C. P. and M. R. Gunson et al., ATMOS/ATLAS 3 infra red profile measurements of trace gases in the November 1994 tropical and subtropical upper troposphere, $J$. Quant. Spectrosc. Radiat. Transfer, 60, 891-901., 1998

Rinsland, C. P. and G. Dufour et al., Atmospheric chemistry experiment (ACE) measurements of elevated Southern Hemisphere upper tropospheric $\mathrm{CO}, \mathrm{C}_{2} \mathrm{H}_{6}, \mathrm{HCN}$, and $\mathrm{C} 2 \mathrm{H} 2$ mixing ratios from biomass burning emissions and long-range transport, Geophys. Res. Lett., 32, L20803, 2005

von Clarmann, T. and B. Funke et al., The MIPAS $\mathrm{HOCl}$ climatology, Atmos. Chem. Phys., 12, 1965-1977, 2012. 